\title{
Integrating Thermal and Hydro Electricity Markets: Economic and Environmental Costs of not Harmonizing Pricing Rules
}

\author{
Etienne Billette de Villemeur* and Pierre-Olivier Pineau**
}

\begin{abstract}
The electricity sector is the largest source of greenhouse gases (GHG) emissions in the world, and reducing these emissions can often be costly. However, because electricity markets remain integrated at a shallow level (with different pricing regulations), many gains from deeper integration (adoption of marginal cost pricing everywhere) are yet to be realized. This paper assesses the benefits of deep integration between a "hydro" jurisdiction and a "thermal" one. It also underscores the inefficiency of trade when pricing rules differ. Our detailed hourly model, calibrated with real data from the provinces of Ontario and Quebec, Canada, estimates price, consumption, emissions and welfare changes associated with fully integrating electricity markets, under transmission constraints. A negative abatement cost of $\$ 37 /$ tonne of $\mathrm{CO}_{2}$ was found (for more than 1 million tonnes), clearly illustrating the untapped potential of wealth creation in carbon reduction initiatives. Furthermore, given the inefficiency of shallow integration between markets, we found that removing interconnections between markets offers a relatively affordable $\mathrm{CO}_{2}$-reduction opportunity, at $\$ 21.5 /$ tonne.
\end{abstract}

Keywords: Market Integration, Regulation, Electricity Trade, Environmental Impacts

http://dx.doi.org/10.5547/01956574.37.1.edev

\section{INTRODUCTION}

While many economic and environmental issues have become global, electricity markets have, to a large extent, remained local. Despite the existence of numerous regional integration initiatives, many obstacles continue to hinder the transformation of electricity markets. In the United States, for instance, in 2005, strong state-level political opposition halted the plan to implement regional transmission organizations (RTOs), all of which following a standard market design (FERC, 2005). Even in Europe, where a 1996 European Union directive set the objective to progressively open the electricity market to create a single market, progress has been slow and plans had to be revised. If standard microeconomic theory would justify removing some regulation and barriers to trade, as many natural monopoly features have disappeared in the electricity sector, only a limited number of states have opted to harmonize their electricity market with that of their neighbors. Such integration would indeed lead to price and quantity adjustments, along with associated political challenges. As was clearly established in an important literature review commis-

* Université de Lille, LEM, CNRS UMR 9221, Cité Scientifique 59655 Villeneuve d’Ascq Cedex, France. E-mail: Etienne.de-Villemeur@univ-lille1.fr.

** Corresponding author. HEC Montréal, Chair in Energy Sector Management, 3000 Côte-Sainte-Catherine Road, Montréal, Quebec, H3T 2A7, Canada. Phone: + 1514 340-6922, E-mail: pierre-olivier.pineau@ @ec.ca. 
sioned by the World Bank (ECA, 2010) to look at regional power sector integration, these issues remain poorly documented. With the introduction of a model for analyzing the impact of trade and of the creation of a common market between two jurisdictions (i.e., the province of Ontario, Canada, where power generation is mainly thermal-based and the province of Quebec, also in Canada, where hydropower provides most electricity), our paper seeks to remedy this situation.

Price, electricity production, consumption levels and GHG emission levels are estimated using various scenarios, permitting integration outcomes to be clearly illustrated. Our results show that if the hydro jurisdiction were to keep its average cost pricing regulation, while the thermal jurisdiction maintained its competitive market model, although trade would slightly improve total welfare, when ignoring GHG emissions, emissions would increase with trade. The welfare improvement would amount to $\$ 21.5$ per tonne, which can also be seen as the GHG abatement cost associated with transmission capacity removal. By contrast, we estimate that a negative abatement cost of $\$ 37$ per tonne could be achieved with greater integration, i.e., if electricity trade were complemented by the implementation of marginal cost pricing in the hydro jurisdiction. The story is however not the same for producers and consumers in both markets: while consumers in the thermal jurisdiction would stand to gain from trade and market harmonization, their counterparts in the hydro jurisdiction would lose out with the end of price regulation. Producers, on the other hand, would lose out with trade in the thermal jurisdiction but increase their profits in the hydro jurisdiction. When transmission capacity increases, all of these impacts increase.

The rest of the paper is divided into four sections. In section 2, we provide a literature review. Section 3 presents the detailed hourly model, empirically calibrated to capture the features of electricity markets in two neighboring jurisdictions: Ontario and Quebec, both in Canada. The Ontarian market is depicted as the competitive "thermal" market, while the Quebec market is depicted as the average cost pricing "hydro" market. Results are discussed in section 4, which is followed by a conclusion.

\section{LITERATURE REVIEW}

To date, most of the literature on electricity market reforms has looked at competition levels, market design, transmission pricing rules and other issues, in a context of isolated electricity markets (see for instance Newbery, 2000, or Stoft, 2002, and the abundant literature they refer to). Despite the important potential benefits of regional electricity market integration, literature on harmonization reforms is limited.

This point is specifically documented in a substantial literature review that was made for the World Bank's Energy Sector Management Assistance Program, ECA (2010). It states that there are "few academic studies which have real theoretical depth [on regional power sector integration]" (ECA, 2010: 2) and that there is a need for "theoretical analysis of the way in which benefits are distributed" (ECA, 2010: 12). This is happening in a context where there exist many initiatives promoting regional power sector integration, especially in developing countries. See for instance WEC (2005) and UNECA (2006) for perspectives from international organizations on energy integration in Africa. UN (2006) attempts to make the case for international electric power grid interconnections, while clearly underscoring potential costs and institutional challenges. World Bank (2010) draws lessons from the study of various integration cases, both in developed and developing nations, and from a literature review (ECA, 2010). The review summarizes the following expected benefits from regional integration: improved economic efficiency (in a broad sense), reduced costs (in operations and investment), improved supply conditions and various possible social, environmental and even political gains (ECA, 2010: 4-5). There is however no mention of any 
rigorous analysis of such benefits or subset of benefits. Some assessments have been made, such as the economic benefits of RTOs in the U.S. (IFC, 2002), but they remain very general and provide little information on the distribution of benefits (among regional producers and consumers) and on environmental impacts. An exception is Finon and Romano (2009), who discuss the impact of market integration on producer's profits, in the lower cost jurisdiction, but welfare is not included in their analysis.

A key issue in electricity market integration is the protection of "native load," which is associated with "end-use customers that the Load-Serving Entity is obligated to serve" (NERC, 2011). In most cases, such obligations come with a regulated price based on local production costs, which can be especially low if large amounts of hydropower are available. In the U.S., federal regulation promoting wholesale competition protects native load by making generation and transmission capacity planned to meet this native load unavailable to non-local purchasers. See in particular the Federal Energy Regulatory Commission (FERC) orders 888 and 890. This ensures that integration remains "shallow," as it only allows limited transactions, and maintains potentially important price differences between neighboring markets.

Our paper presents a two-market model for assessing "shallow" and "deep" integration, to use the World Bank (2010) terminology. In the first case, the two jurisdictions are interconnected but keep their distinct market organization: one is competitive and the other follows an averagecost pricing regulation. In the second case, both jurisdictions are competitive: native load commitments are removed. Changes in outcomes can clearly be observed from the three integration regimes: no interconnection (autarky), shallow and deep integration.

The paper's contribution is twofold. First, it proposes a model for straightforward comparison of shallow and deep integration outcomes, with detailed impacts on consumers, producers and emission levels. Second, it provides empirically-based welfare estimates of GHG abatement costs in the electricity sector. By including transmission constraints and costs, it also captures their impact upon the electricity trade.

The paper builds on a stream of articles dealing with associated topics. Billette de Villemeur and Pineau (2010) identified conditions under which trade between two jurisdictions is environmentally damaging, without, however, looking at any change in market organization. Billette de Villemeur and Pineau (2012) focused on such market changes (integration regime changes), but from a purely theoretical perspective, and without considering intertemporal arbitrage in the hydro jurisdiction. In Billette de Villemeur and Pineau (2012), a key result is that deep integration, as compared to shallow integration, yields a decrease in total consumption and an increase in the overall welfare. This result is empirically illustrated in this paper, further making the point that deep integration could be beneficial, especially from an environmental perspective.

Intertemporal arbitrage possibilities are studied in Billette de Villemeur and Vinella (2011), but in a single market. The current paper uses, and expands upon, the model found in Førsund (2007). However, in his study of hydropower economics, Førsund did not look at a regulated hydro jurisdiction trading with a competitive one, as is the case here. The Førsund model was recently used in Green and Vasilakos (2012) to study wind and hydro trade between Denmark and Norway. These two countries have a competitive market. In this paper, we look at Ontario and Quebec, two neighboring Canadian provinces that are engaged in trade, but with very different pricing rules.

\section{TRADE IN ELECTRICITY MARKETS: A MULTI-PERIOD ANALYSIS}

Our model, which is formally presented in section 3.2, focuses on the role of hydropower, which requires multiple periods when storage is available. Indeed, thermal electricity is seldom 
constrained by the available quantity of primary energy (uranium, coal, natural gas or oil) and, as compared to demand fluctuations, production costs are essentially stationary. Market equilibrium analysis can thus legitimately be performed in a static framework when the entire electricity supply stems from thermal technologies. By contrast, hydropower supply is almost completely inelastic, due to the exogenous character of water provision (i.e., water inflow from rainfall). When a dam is used, hydro production can be easily modulated to meet time-varying demand. Indeed, water reserves can be almost freely allocated across time if there is sufficient storage capacity. There is thus room for arbitraging, whatever the objective of the utility. As pointed out by Billette de Villemeur and Vinella (2011), this gives hydropower an important role in the workings of electricity markets, beyond that related to its actual market share.

The high investment costs and the low marginal costs linked to hydroelectricity generation make power plants "natural monopolies," in relatively small and isolated electricity markets. This may explain why, in hydro-dominated electricity markets, the price of electricity is very often regulated. More generally, this calls for specific competition policies in jurisdictions where generation is predominantly hydro-based (see Rangel, 2008).

The persistence of price regulation has very important consequences for market integration outcomes. In fact, assuming price regulation in the hydropower jurisdiction (hereafter referred to as $H$ ), neither price nor demand should vary in $H$ with the introduction of trade. Hence, absent over-production or rationing, the sum of the trade flows should add up to exactly zero (no "loss of resource" for $H$ consumers). As a result, total production in the thermal jurisdiction (hereafter referred to as $T h$ ) is also equal to total consumption in this jurisdiction. Thus, the sole consequence of "shallow integration" is intertemporal redistribution of production, thanks to the possible arbitrage offered by hydropower. Clearly, without demand fluctuations, there is no room for trade. If instead price varies in $T h$, intertemporal arbitrage may help to improve both efficiency and profitability, even if the $H$ producer has native load commitments.

The introduction of trade has radically different consequences when integration is deep, i.e., if, after the introduction of trade, prices are market-based in both jurisdictions. In fact, both the removal of price regulation and the interaction with a trading partner with higher production costs would lead to a price increase in $H$. Thus, while total hydropower supply remains unchanged because it is completely independent from the pricing policy in the short run, there is a positive net power outflow from $H$ to $T h$. It follows that price decreases in $T h$ and that thermal electricity would represent a fraction of consumption in Th. Importantly, these gross effects add up to the intertemporal arbitrage already evidenced in the case of "shallow" integration. This explains the importance of adopting a multi-period model, even for the analysis of the latter case.

To make the results clearer, we will assume that $T h$ (Ontario) holds no hydro storage capacity while $H$ (Quebec) only produces hydropower with a storage capacity (we ignore multiyear water management aspects). We focus on this particular case in order to provide figures and to illustrate our theoretical results (see Billette de Villemeur and Pineau, 2010 and 2012) and their multi-period extension. Our results are however of general interest, as the modeled situation is far from unique: British Columbia, another Canadian province with regulated hydropower and storage capacity, actively trades with Alberta, its competitive thermal neighbor, as well as with its Southern U.S. neighbors. In the United States, large hydro provides more than $66,000 \mathrm{MW}$ of capacity (EPRI, 2007 ) and with $73 \%$ of this hydro owned by federal and non-federal public organizations (Hall and Reeves, 2006), most of this power is sold at average cost instead of market price.

We now offer some additional background information on Ontario and Quebec, before presenting the three trade regimes of interest, along with the formal model. In a third subsection, we present the detailed outcomes of our calibrated model.

Copyright (C) 2016 by the IAEE. All rights reserved. 


\subsection{Description of the Two Markets}

Ontario and Quebec are two neighboring Canadian provinces. Despite its larger population of 12.8 million (against 7.7 million for Quebec), Ontario has significantly less power generation capacity: 31,056 MW in 2007 (IESO, 2007) compared to 46,220 MW for Quebec (MRNF, 2009). The structure of the two markets is also very different, notably because Ontario relies on all types of power generation capacities (mostly thermal however), while Quebec relies almost exclusively on hydropower (92\% of its capacity). Its main hydroproducer has a yearly production of about 190 TWh, with a storage capacity of $175 \mathrm{TWh}$ (Hydro-Québec, 2008). ${ }^{1}$ Ontario has an hourly price set in a competitive spot market (with some share of its generation still sold at a regulated price; see IESO, 2009), which resulted in an average hourly price of \$47.81/MWh in 2007 (IESO, 2008a). In Quebec, all electricity is sold at a regulated price that is close to $\$ 27.90 / \mathrm{MWh}^{2}$ This price represents the estimated cost of the "heritage pool" of 165 TWh reserved for Quebec consumers (Hydro-Québec, 2008). Because many suppliers compete in the Ontarian spot market, while HydroQuébec dominates in Quebec (88\% of overall production), these two markets are a good illustration of the theoretical context we wish to study. Furthermore, electricity is traded over transmission lines that can supply up to 1,295 MW from Quebec to Ontario, and up to $720 \mathrm{MW}$ from Ontario to Quebec (HQ TransÉnergie, 2006). This interconnection only changed in 2010 with the addition of about 1,000 MW of transmission capacity in both directions. The situation between the two provinces represents a "mixed market structure with trade" (or shallow integration): Ontario sells electricity at marginal cost within its borders and Quebec at average cost. Exports and imports are done at Ontario's marginal cost, unless transmission constraints are binding.

We focused on the Ontario-Quebec trade relationship despite many other interconnections (for both jurisdictions) for a variety of reasons: there is a lot of data available on the Ontarian market; Quebec's hydropower capacity and production are very important (and could have regional implications if managed differently); there is an active and still developing electricity trade history between Ontario and Quebec; and, finally, it would probably be easier to harmonize pricing rules within one country than across country borders. This being said, nothing in our empirical choice is central to the core findings of our paper. We could have used the Quebec-New York or British Colombia-Alberta situations for illustrative purposes.

\subsection{The Model}

For our analysis, we adopted the multi-period "bathtub" framework introduced in Førsund (2007). This model uses fixed capacity and is not intended to explore capacity investment issues. The original model provides a simple way to analyze the "optimal" use of hydro and thermal generators over several jurisdictions with varying demand. Absent externalities, if markets are competitive everywhere, the constrained optimization problem that maximizes social welfare gives rise to a solution that also corresponds to the market equilibrium outcome. This explains why Førsund's framework is also used as a tool for positive analysis, e.g., to analyze the actual effect

1. BC Hydro, by comparison, produces about $50 \mathrm{TWh}$ of hydropower and usually keeps more than $10 \mathrm{TWh}$ in storage (BC Hydro, 2012).

2. $165 \mathrm{TWh}$ are sold at this price, and the remaining energy is either produced or purchased at a different cost. The final energy price to consumers is the average procurement cost, which remains close to $\$ 27.90 / \mathrm{MWh}$. If more trade occurs because of increased transmission capacity (see section 4.2), this price remains the reference price in the hydro jurisdiction. 
of competing hydro, thermal and wind generators on price and demand patterns. See Førsund et al. (2008) and Green and Vasilakos (2012).

Our contribution consists precisely in studying the consequences of having electricity markets that are not competitive everywhere. We evidence however that, even if average cost pricing prevails in one market, the framework can easily be adapted for the equilibrium outcome to still correspond to the solution of a (slightly modified) optimization problem. This allows us to use a unified approach to address the issue of market integration when institutional arrangements differ across jurisdictions.

Generation takes place within two provinces, thermal $(T h)$ and hydro $(H)$, as characterized by their dominant technology. More precisely, in $T h$, while nuclear energy provides the base load, most power is generated by generators endowed with a thermal technology (coal, gas). ${ }^{3} e_{t}^{T h}$ denotes electricity production in $T h$ at period $t . C_{T h}\left(e_{t}^{T h}\right)$ denotes industry-wide production cost function. Since the cost function is considered at the aggregate level and total consumption in $T h$ never exceeds production capacity, there is no need to introduce capacity constraints. ${ }^{4}$

In $H$, electricity generation almost exclusively stems from hydropower. $e_{t}^{H}$ denotes electricity production in $H$ at period $t$. Hydro generators have a marginal cost of zero. Yet, fixed costs are important. We also introduce the (infrastructure, operations and maintenance) costs $C_{H}$ linked to production in $H$. Although they play no role in the time distribution of energy production, they determine the (regulated) price in $H$. Obviously, yearly production cannot exceed the total available water in reservoir $W$, measured in MWh (a normalization). ${ }^{5}$ This yields the following constraint:

$$
\sum_{t=1}^{8760} e_{t}^{H} \leq W
$$

where, in our data, $t$ indexes the 8,760 hours of the year 2007.

There is a well-organized power market in Th. Hence, we assume that all generators in this jurisdiction behave competitively. Power is thus priced at marginal costs and we have:

$$
p_{t}^{T h}=C_{T h}^{\prime}\left(e_{t}^{T h}\right),
$$

where $p_{t}^{T h}$ stands for the price of power in jurisdiction $T h$ at period $t$. By contrast, $p_{t}^{H}$, the price of power in jurisdiction $H$ at period $t$ is supposed to be regulated, at least in some scenarios (our regimes 1 and 2). If so, the price $p_{R}^{H}$ is assumed to be equal to the average cost and constant over a year, as is the case in regulated electricity markets. ${ }^{6}$

3. Since Ontario progressively phased-out coal power plants after 2007, 2014 is the last year of coal consumption for electricity generation in Ontario, see Pineau (2013).

4. Indeed, with the so-called "reserve margins requirements" (imposed for system reliability), there is excess capacity in most power systems, as is the case in Ontario. In 2013, this reserve margin was $18 \%$-meaning that total capacity was $18 \%$ above peak demand (IESO, 2013). As we are interested in resource allocation within a given system of two interconnected jurisdictions with no capacity shortage, and not in capacity addition within this system, ignoring capacity constraints for generation has no influence on our results.

5. The available water for the year is assumed to be equal to the yearly average water inflows from rainfalls in reservoirs, treated as a single one with perfect maneuverability in our model.

6. Regulated electricity rates are usually changed once a year, and remain constant otherwise. See for instance the regulated rate pages of two "hydro" power systems: Hydro-Québec (http://www.hydroquebec.com/residential/understanding-your-bill/rates/residential-rates/rate-d/) and Seattle City Light (http://www.seattle.gov/light/Accounts/Rates/ac5_ erps25_1.htm). This is also the case for the nuclear-dominated system in France (http://particuliers.edf.com/offres-d-energie/ electricite-47378.html).

Copyright (C) 2016 by the IAEE. All rights reserved. 
Exports from $T h$ (into $H$ ), $x_{t}^{T h}$, and imports into $T h$ (from $H$ ), $x_{t}^{H}$ are supposed to be traded at the price $p_{t}^{T h}$ on the $T h$ market. We however allow for transmission $\operatorname{costs} c^{\tau}$ so that trade does not occur if the price differential across jurisdictions is not large enough. As usual, we follow the convention that both jurisdictions cannot export at the same time. However, we account for the fact that transmission capacity is direction specific. Moreover, availability varies across time. We account for both aspects by introducing $\bar{x}_{t}^{T h}$, and $\bar{x}_{t}^{H}$ the time-specific upper-limits of $x_{t}^{T h}$ and $x_{t}^{H}$, respectively.

There is a (varying) demand in each jurisdiction, $D_{t}^{T h}\left(p_{t}^{T h}\right)$ and $D_{t}^{H}\left(p_{t}^{H}\right)$. We assume that their respective inverse demand functions $p_{t}^{T h}\left(D_{t}^{T h}\right)$ and $p_{t}^{H}\left(D_{t}^{H}\right)$ provide the marginal (social) value of power in each jurisdiction.

This paper is intended to study the effect of "shallow" and "deep" integration of electricity markets on prices, quantities, firm profits and consumer welfare. More precisely, we aim to compare three different regimes:

- Regime 1, with a "mixed" market structure ${ }^{7}$ and both jurisdictions in autarky (no transmission capacity).

- Regime 2 (shallow integration), with still a "mixed" market structure, but where trade is possible with transmission constraints.

- Regime 3 (deep integration), where markets are fully integrated, albeit with transmission constraints. These constraints may prevent the price across jurisdictions from remaining unique, but marginal cost pricing prevails everywhere.

The shift from regime 2 to regime 3 corresponds to an institutional change in $H$ that would result in pricing power at the marginal water value $(\lambda)$. This is made explicit in the next section. Note that such a change does not necessarily entail a complete reorganization of the industry (i.e., the fragmentation of the monopoly and the creation of a power market). It may simply stem from a change in regulatory policies.

The two markets are studied as if they are independent from other neighboring markets. Hence, we considered "other" commercial exchanges as being part of each jurisdiction; i.e., imports from other jurisdictions were deemed to be produced within the jurisdiction, while exports were considered to be consumed in it.

\subsubsection{Optimal water use in a regulated market}

For an average cost pricing policy to be implemented effectively, it requires more than a set price. Some supply obligation constraints also have to be introduced. This is especially true if energy operators are allowed to trade with other jurisdictions. In fact, producers will privilege markets that offer better opportunities, while restraining (and possibly cutting) their supply to less profitable markets. This explains why, wherever there is price regulation, operators are also subject to other obligations regarding energy provision.

In this paper, we assume that the regulated producer in $H$ has a supply obligation towards all clients within the jurisdiction (see equation 4). It is also assumed that the (regulated) price $p_{H}$ is set at the average cost of providing energy to all its clients. Thus, in $H$, price and consumption do not dependent on water allocation; moreover, the sole (unregulated) profits of the regulated operator are derived from trade.

7. Competitive market in $T h$, while in $H$, average cost pricing prevails. 
By definition, energy balance in the system requires that, at each moment $t$ :

$$
\begin{aligned}
& D_{t}^{T h}\left(p_{t}^{T h}\right)=e_{t}^{T h}+x_{t}^{H}-x_{t}^{T h}, \\
& D_{t}^{H}\left(p_{t}^{H}\right)=e_{t}^{H}+x_{t}^{T h}-x_{t}^{H} .
\end{aligned}
$$

The energy production $\left(e_{t}^{T h}, e_{t}^{H}\right)$ and trade flow $\left(x_{t}^{T h}, x_{t}^{H}\right)$ patterns are chosen by the operators so as to maximize profits. This comes with several limitations. The first constraints are related to the capacity of both the thermal and hydro generators. As they are almost never binding, due to reliability margins, we ignored them from the outset. Hydro production also has limitations linked to the replenishment of reservoirs. ${ }^{8}$ Again, we ignored them because as long as there is accessible storage capacity, they are irrelevant to our study. Other constraints however are not purely theoretical. In particular, as already stated in (1), yearly hydropower production cannot exceed the total amount of available water. $\lambda$ denotes the shadow value of this constraint, to be interpreted as the (implicit) "price of water." The observation of the trade pattern across jurisdictions also makes it clear that transmission capacity constraints can be binding. $\mu_{t}$ denotes their (time-specific) shadow value. $^{9}$

Transmission capacities are small enough for the hydro producer to be seen as a pricetaker provider (or buyer) in the competitive $T h$ market. Water availability and energy provisions obligations make it clear that the hydro producer may freely trade $x_{t}=x_{t}^{H}-x_{t}^{T h}$ on the Th market, provided that:

$$
\sum_{t=1}^{8760} x_{t} \leq W-\sum_{t=1}^{8760} D_{t}^{H}\left(p_{R}^{H}\right),
$$

where $p_{R}^{H}$ is set by the regulator. It follows that:

Proposition 1. Computing the equilibrium in regime 2 amounts to solving the optimization program:

$$
\begin{aligned}
& \max _{\left\{e_{t}^{T h}, x_{t}^{T h}, x_{t}^{H}\right\}_{t=1, \ldots, 8700}}\left\{\sum_{t=1}^{8760}\left[\int_{0}^{e_{t}^{T h}+x_{t}^{H}-x_{t}^{T h}} p_{t}^{T h}(q) d q-C_{T h}\left(e_{t}^{T h}\right)-c^{\tau} x_{t}^{T h}-c^{\tau} x_{t}^{H}\right]\right\} \\
& \text { s.t. } \sum_{t=1}^{8760}\left(x_{t}^{H}-x_{t}^{T h}\right) \leq W-\sum_{t=1}^{8760} D_{t}^{H}\left(p_{R}^{H}\right) \text { and }-\bar{x}_{t}^{T h} \leq x_{t}^{H}-x_{t}^{T h} \leq \bar{x}_{t}^{H}
\end{aligned}
$$

all $t=1, \ldots, 8760$.

This proposition is adapted from Førsund (2007), with the inclusion of a regulated hydro producer and transmission costs $\left(c^{\tau}\right)$. Note that to characterize regime 1 , one must simply set the transmission capacities to zero: $\bar{x}_{t}^{T h}=\bar{x}_{t}^{H}=0$.

8. Replenishment cannot go beyond reservoir capacity and below a minimum level, generally resulting from environmental considerations. Also, the water level in a reservoir has an influence on the production level, due to differences in height.

9. Because we assume that both jurisdictions cannot export at the same time, there is no need to introduce a multiplier for each of the (direction specific) transmission capacities. 
Absent transmission constraints, price patterns are easily characterized. If $x_{t}^{H}>0$, then $p_{t}^{T h}=\lambda+c^{\tau}$; if $x_{t}^{T h}>0$, then $p_{t}^{T h}=\lambda-c^{\tau}$; if $x_{t}^{T h}=x_{t}^{H}=0$, then:

$$
\lambda-c^{\tau} \leq p_{t}^{T h}=C_{T h}^{\prime}\left(e_{t}^{T h}\right) \leq \lambda+c^{\tau} .
$$

Hence, despite abundant hydro resources, price fluctuations may arise in a power system solely as a result of transmission costs. This is consistent with the observation that transmission constraints are rarely binding, while prices are almost never identical even in adjacent periods; see Pineau and Lefebvre (2009).

Limited transmission capacities may explain why the presence of hydropower is not sufficient to prevent extreme price fluctuations. We establish the following characterization of regime 2 prices:

Proposition 2. In regime 2, when $T h$ is exporting, the price in $T h$ is at most $\overline{p_{T h}}=\lambda-c^{\tau}$. When $T h$ is importing, the price in $T h$ is no less than $\underline{p_{T h}}=\lambda+c^{\tau}$. If $x_{t}^{T h}=x_{t}^{H}=0$ then:

$$
\overline{p_{T h}}<p_{t}^{T h}=C_{T h}^{\prime}\left(e_{t}^{T h}\right)<\underline{p_{T h}}
$$

Proof. See appendix 1.

Observe that the shadow price of water $\lambda=(\partial L / \partial W)$ differs a priori from the regulated price $p_{R}^{H}$. Because the hydro producer in $H$ is actually arbitraging between high-price and low-price periods in $T h$, it may well be the case that $x_{t}^{T h}>0$ and $p_{t}^{H}=p_{R}^{H}<p_{t}^{T h}$ Yet, the values of $\lambda$ and $p_{R}^{H}$ are not completely unrelated. The higher the $p_{R}^{H}$, the lower consumption in $H$ the greater the propensity to export toward $T h$, and thus the smaller $\lambda$. The environmental impact of trade in regime 2 depends on many factors, particularly demand and supply elasticity as well as emission intensity for different production levels. Such impacts were studied in Billette de Villemeur and Pineau (2010) and some additional results are presented later in this paper (see in particular Tables 5 and 9).

\subsubsection{Comparison of shallow and deep integration}

In the deep integration regime (regime 3), native load commitments are removed from $H$, and both jurisdictions apply marginal pricing policies. This situation was already studied by Førsund (2007) see in particular his problems 6.26 and 6.29. We restate his results for ease of comparison with regime 2 :

Proposition 3. (Førsund, 2007)—Computing the equilibrium in regime 3 amounts to solving the optimization program:

$$
\begin{aligned}
& \max _{\left\{e_{t}^{T h}, e_{t}^{H}, x_{t}^{T h}, x_{t}^{H}\right\}_{t=1, \ldots, 8760}}\left\{\begin{array}{c}
\sum_{t=1}^{8760}\left[\int_{0}^{e_{t}^{T h}+x_{t}^{H}-x_{t}^{T h}} p_{t}^{T h}(q) d q-C_{T h}\left(e_{t}^{T h}\right)-c^{\tau} x_{t}^{T h}-c^{\tau} x_{t}^{H}\right] \\
+\sum_{t=1}^{8760} \int_{0}^{e_{t}^{H}+x_{t}^{T h}-x_{t}^{H}} p_{t}^{H}(q) d q-C_{H}
\end{array}\right\} \\
& \text { s.t. } \sum_{t=1}^{8760} e_{t}^{H} \leq W \text { and }-\bar{x}_{t}^{T h} \leq x_{t}^{H}-x_{t}^{T h} \leq \bar{x}_{t}^{H},
\end{aligned}
$$


all $t=1, \ldots, 8760$.

If welfare comparisons are to be made across regimes, the gross surplus of consumers in $H$ and the costs of hydro-production must be added to the program presented in Proposition 1 to study shallow integration:

$$
\sum_{t=1}^{8760} \int_{0}^{D_{t}^{H}\left(p_{R}^{H}\right)} p_{t}^{H}(q) d q-C_{H}
$$

This constant term was cut out because it clearly has no effect on water allocation.

It should be clear that overall welfare will be higher in the deep integration regime than in the shallow one. The "augmented" program of Proposition 1 differs from that of Proposition 3 by the sole addition of the constraints

$$
e_{t}^{H}+x_{t}^{T h}-x_{t}^{H}=D_{t}^{H}\left(p_{R}^{H}\right)
$$

The shift from regime 2 to regime 3 could meet with resistance, since the overall improvement that would follow such a change would not necessarily benefit all stakeholders.

The structure of the price pattern is identical in both regimes, with the only difference being that the "price of water" $\lambda$ would now be equal to the prevailing equilibrium price in $H$, denoted as $p_{e}^{H}$. This says that the threshold prices $\overline{p_{T h}}$ and $p_{T h}$ differ a priori.

Proposition 4. In regime 3, when $T h$ is exporting, the price in $T h$ is at most $\overline{p_{T h}}=p_{e}^{H}-c^{\tau}$. When $T h$ is importing, the price in $T h$ is no less than $\underline{p_{T h}}=p_{e}^{H}+c^{\tau}$. If $x_{t}^{T h}=x_{t}^{H}=0$ then:

$$
\overline{p_{T h}}<p_{t}^{T h}=C_{T h}^{\prime}\left(e_{t}^{T h}\right)<\underline{p_{T h}} .
$$

Proof. See appendix 2.

Notably, the price in $H$ remains constant even after price regulation is removed. Indeed, price volatility is usually an important characteristic of deregulated electricity markets (see for instance Zareipour et al., 2007). One could thus fear that it would be a necessary outcome of deregulation in $H$. Our paper shows that this is not so. The intuition behind this result is however straightforward: if the price in $H$ was higher during some hours, then (price taker) producers would simply sell more during these hours, driving down the price with additional supply. If, on the contrary, the price was lower during some hours, supply would contract, and the price would increase. This is of course only possible in a hydro system with enough storage and constant production costs, where water power can be freely allocated across time periods. The price in $H$ is the marginal value of water over the entire horizon considered.

\subsection{Model Calibration}

In the following subsections, we provide details on the model's calibration. Real supply and demand data for Ontario and Quebec were used, along with some necessary assumptions and approximations regarding production costs and constraints, demand elasticity and emissions. 


\section{Figure 1: Monthly Peak Demand and Total Monthly Consumption}

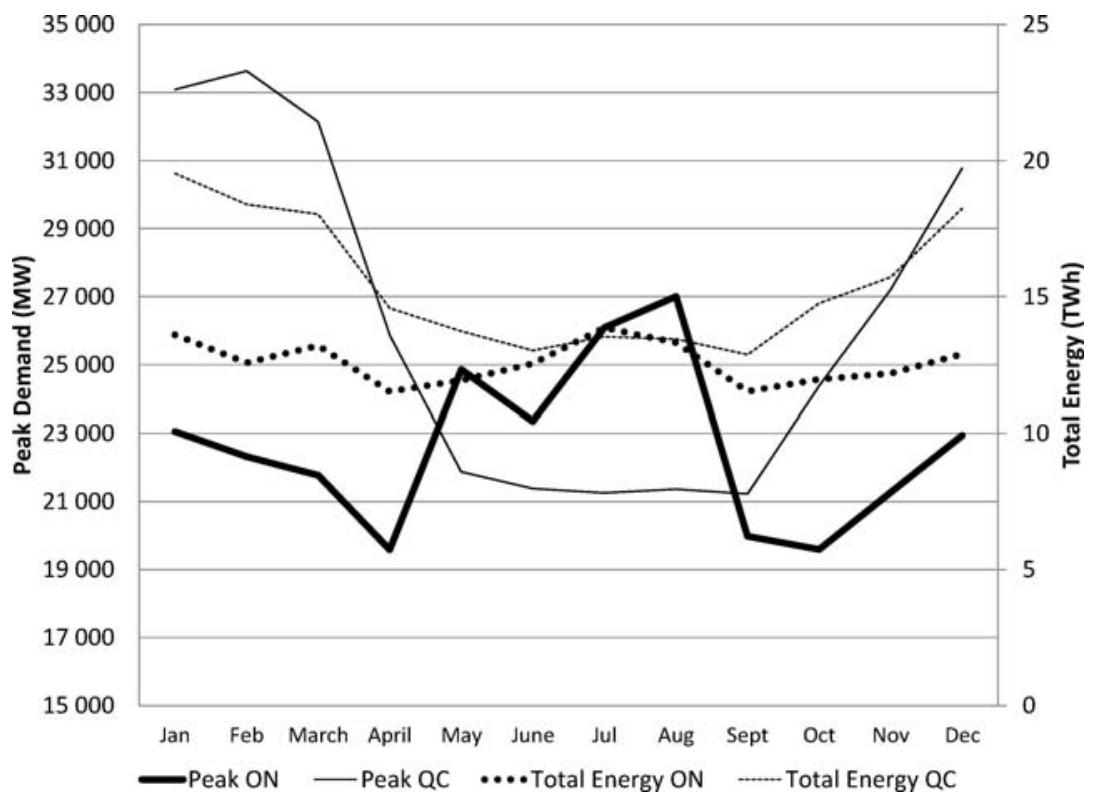

\subsubsection{Demand Data for Ontario and Quebec}

Because the Ontario electricity market is open and competitive, hourly demand and price data are publicly available on the Ontario Independent Electricity System Operator (IESO) website. Hydro-Québec does not release hourly demand information, but has to share monthly data on its peak load and total energy supply with the North American Electric Reliability Corporation (NERC) (NERC, 2008). Figure 1 illustrates peak demand and total monthly consumption for both markets. It can be observed that peak demand and energy consumption is higher in Quebec during winter, due to heating needs. This represents a major difference between the Quebec and Ontario electricity systems. This pattern is reversed during the summer, due to air conditioning needs. In 2007, total power demand was 152.206 TWh in Ontario and 185.828 TWh in Quebec (IESO, 2008b, NERC, 2008). As we needed hourly data for the Quebec market, but did not have access to such information, these data were estimated. Knowing the monthly total consumption and peak load for Quebec, and taking into account the fact that daily load patterns in Ontario and Quebec are mostly similar due to the proximity of both markets, hourly demand data were reconstructed for Quebec, based on the Ontario demand pattern. See Appendix B for more details on how this was done. The fact that Quebec has a winter peak and Ontario a summer one does not pose a problem for the data reconstruction. This is because daily load curves have the same shape: low night loads, morning and evening peaks with a "shoulder" load between them.

Using these hourly price and demand values, 8,760 linear hourly demand curves were estimated for each hour $t$ in each province:

$$
\begin{aligned}
& D_{t}^{T h}=a_{t}^{T h}-b_{t}^{T h} p_{t}^{T h}, \\
& D_{t}^{H}=a_{t}^{H}-b_{t}^{H} p_{t}^{H} .
\end{aligned}
$$


Table 1: Generation Capacity in Ontario and Quebec

\begin{tabular}{lccrr}
\hline & ON Capacity (MW)* & Capability Factor & Production Factor & QC Capability (MW)** \\
\hline Coal & 6,285 & $68 \%$ & $42 \%$ & 0 \\
Natural Gas & 2,766 & $90 \%$ & $54 \%$ & 550 \\
Hydro & 7,906 & $92 \%$ & $45 \%$ & 42,640 \\
Nuclear & 11,365 & $81 \%$ & $75 \%$ & 675 \\
Oil & 2,100 & $79 \%$ & $5 \%$ & 1,470 \\
Wind & 409 & $100 \%$ & $30 \%$ & 431 \\
Wood Waste & 225 & $81 \%$ & $48 \%$ & 454 \\
\hline TOTAL & 31,056 & & 46,220 \\
\hline
\end{tabular}

*IESO (2007) **MRNF (2009) and Hydro-Québec Production (2009)

In addition to price and quantity data, a price elasticity value of -0.15 was used to compute the values of parameters $a_{t}^{j}$ and $b_{t}^{j}(j=T h, H)$. This elasticity value reflects the short-term (in)elasticity of electricity consumption. See Lijesen (2007) for a survey of price elasticity in the electricity sector.

\subsubsection{Supply and Marginal Cost Data}

Table 1 presents the breakdown of nominal generation capacities in Ontario and Quebec. Capacity data is however not always technically available (as indicated by the "capability factor") and even less used (as indicated by the "production factor"). The capability factor reflects maintenance and occasional breakdowns. The production factor signals that it can be either uneconomical or impossible to produce. Ontarian data for the capability and production factors were taken from IESO, 2007. Nothing is shown for Quebec, as there is no publically available data on capability and production factors for this province.

The following assumptions were made in order to keep the supply side model simple. Ontario nuclear and hydro capacities are bundled and represent 12,694 MW of capacity (after capability and production factors are taken into account). This is justified by the fact that most hydropower in Ontario is run-of-river hydro with no storage capacity. Applying the capability factor to thermal production, we allow for only 4,265 MW of coal capacity and 4,145 MW of combined natural gas and oil capacity. Wind and wood waste were not modeled because they only represent a small share of the capacity in Ontario ( $2 \%$, and even less of actual energy production).

For Quebec, no capacity constraint was used, but an energy constraint was defined: 184.705 TWh of hydroelectricity can be produced. This value was taken from Quebec's 2007 electricity demand (185.828 TWh, from NERC, 2008) minus net imports from Ontario (1.123 TWh, from HQ TransÉnergie, 2009). This is a realistic constraint, given that the actual peak load in 2007 was less than 35,000 MW (see Figure 1), for a production capacity of 46,220 MW. Furthermore, hydropower production in Quebec is limited by water availability more than by actual plant capacity. We assume away thermal and wind generation, which represent less than $8 \%$ of capacity (and even less of actual energy production). ${ }^{10}$

10. Thermal production in Quebec was dominated by nuclear power, which represented only $3 \%$ of total production in 2007. Much of the remaining is off-grid supply to remote communities in Northern regions. In 2007, combustion turbines represented less than $2 \%$ of Quebec's total dispatched production (Statistics Canada, 2009). 


\section{Figure 2: Marginal Production Cost Estimate for Generation in Ontario}

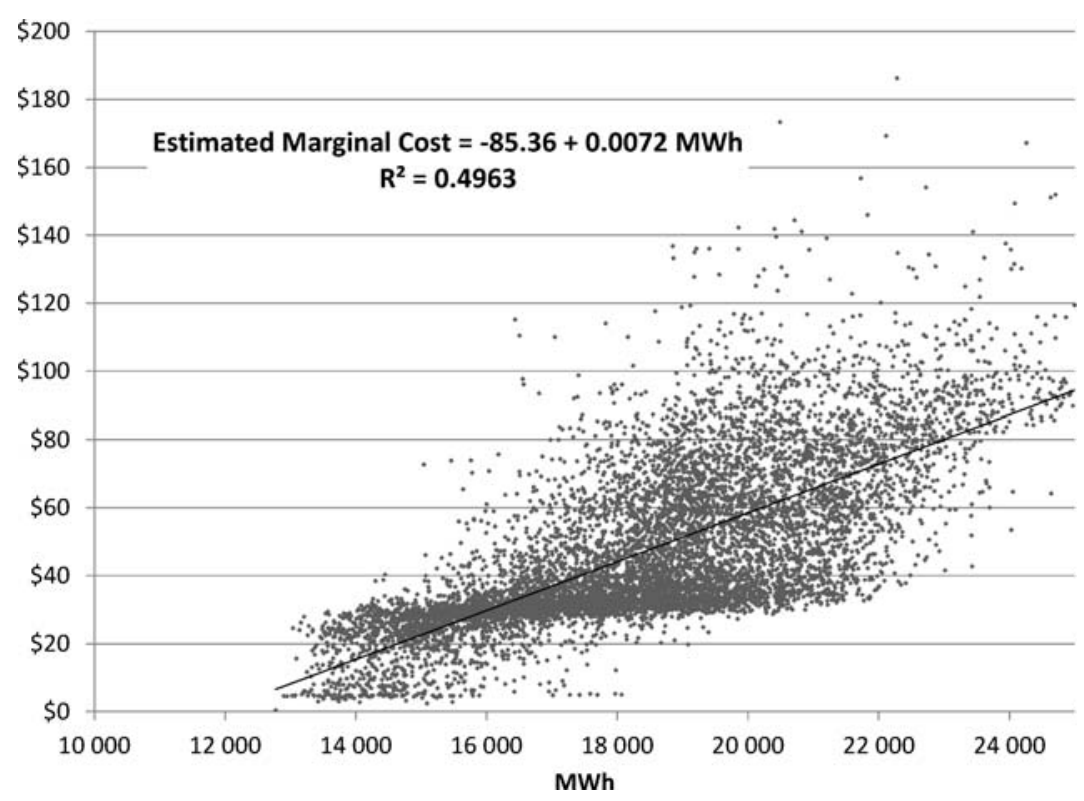

Ontario marginal production costs, which determine what technology is used on an hourly basis, were modeled in two parts. First, the nuclear marginal production cost was set at \$4.6/MWh. ${ }^{11}$ This is an estimate of the combined fuel and operation and maintenance (O\&M) costs of nuclear production (see for instance EIA, 2007: 77 and IEA, 2005:44). Second, the marginal production cost for thermal production was assumed to increase linearly as greater thermal capacity is used. Real 2007 price data were used to estimate this part of the Ontario marginal cost curve. Figure 2 illustrates price-quantity pairs for the 8,760 hours in 2007, in Ontario. A simple linear regression of observed prices and loads in Ontario provided parameters for the second part of the marginal cost function.

Quebec's marginal production cost was set at \$3.3/MWh, which was the estimated variable operation and maintenance cost for hydropower in EIA (2007: 77).

\subsubsection{Fixed Cost Data}

EIA (2007) provides some estimates of investment and fixed O\&M costs for various generation technologies (see Table 2). Using these estimates, the economic lifetime of these technologies and the discount rate of $6 \%$, an annual fixed cost per MW can be estimated for each technology.

Using real capacities for Ontario and Quebec and the above numbers, the annual fixed cost for the Ontarian electricity industry was estimated at $\$ 3.102$ billion and at $\$ 4.219$ billion for Quebec.

11. This cost actually covers combined nuclear and hydro production in Ontario. As already mentioned, there is less flexibility in using hydropower in Ontario compared to Quebec. Due to a lack of water storage capacity, both nuclear and hydro production in Ontario are "must run." 
Table 2: Technology Cost Parameters

\begin{tabular}{|c|c|c|c|c|}
\hline & Economic Lifetime (Years) & $\$, 000 / \mathrm{MW}$ & Fixed O\&M \$/MW & Annual Cost $\$ / \mathrm{MW}$ \\
\hline Coal & 40 & 1,290 & 25,910 & 85,735 \\
\hline Natural Gas & 25 & 594 & 11,010 & 46,466 \\
\hline Hydro & 60 & 1,500 & 13,140 & 92,813 \\
\hline Nuclear & 40 & 2,081 & 63,880 & 138,306 \\
\hline Oil & 40 & 420 & 11,400 & 27,913 \\
\hline Wind & 20 & 1,202 & 28,510 & 104,795 \\
\hline Wood Waste & 40 & 1,869 & 50,180 & 124,216 \\
\hline
\end{tabular}

\subsubsection{Transmission Constraints and Cost}

In 2007, the operating security limit for exports from Quebec to Ontario was 1,295 MW, while it was $720 \mathrm{MW}$ for Quebec imports from Ontario. Actual hourly maximum transmission capacities differ from these numbers. HQ TransÉnergie (2009) provides these capacities for each hour of the year. These can be used to set maximum import and export quantities. However, observed exports and imports show that transmission lines are only used, on average, at $29.9 \%$ of their full capacity for Quebec exports (to Ontario) and at 53.2\% of their full capacity for Quebec imports (from Ontario). This is likely due to transmission constraints related to grid topology, which are not modeled here. In order to better calibrate trade in the model and to better reflect real market outcomes, hourly transmission capacities were adjusted by a ratio set such that the aggregated modeled export and import values matched those observed.

A transaction cost of $\$ 2 / \mathrm{MWh}$ of traded electricity was applied. This cost, which is not easily measured, is only an estimate. Indeed, electricity sellers in Ontario are not charged transmission fees: the Ontario Provincial Transmission Service Rate only applies to consumers withdrawing electricity from the network. Ontarian exporters, however, must pay a $\$ 1 / \mathrm{MWh}$ "Export Transmission Service Rate.” In Quebec, a \$8.22/MWh Non-Firm Point-to-Point Transmission Service fee has to be paid to HQ TransÉnergie. However, as Hydro-Québec dominates the markets and is the principal trader, this fee is charged by one division (transmission) to another (production), and does not affect the company's overall profitability.

\subsubsection{Emission Data and Marginal Damage}

In 2007, GHG emissions from electricity production in Ontario and Quebec were respectively 34 million tonnes (Mt) and 1.95 Mt (Environment Canada, 2009). On average, coal production in Ontario is responsible for about $0.94 \mathrm{t} / \mathrm{MWh}$, while natural gas production emits about half, 0.43 t/MWh (Environment Canada, 2008). ${ }^{12}$ We only report these two numbers because emissions from other sources are not significant.

Estimates for the social marginal damage of a tonne of GHG vary greatly. IPCC (2007) reports estimates from $-\$ 3$ to $\$ 95 / t$, with an average of $\$ 12 / t$. Tol (2005) analyzed 28 peer-reviewed marginal damage cost estimate studies, and found an average value of $\$ 93 / \mathrm{t}$, while the median is $\$ 14 /$ t. In both cases, these values were characterized by high uncertainty.

12. Specific GHG intensity by electricity production source (in $\mathrm{g} \mathrm{CO}_{2}$-eq/kWh) is not reported for 2007 in Environment Canada (2009). Instead, we use Ontario's 2006 values from Environment Canada (2008), which reports them. 
To provide an order of magnitude from a Canadian perspective, British Colombia implemented a carbon tax in 2008, which reached a value of \$30/t in 2012 (Province of British Columbia, 2009). On a different continent, GHG credits for December 2009 were trading at $10.05 €$ in the European Climate Exchange on February 9, 2009. Credits for future years were trading at higher prices, reaching $13.70 €$ for a December 2014 credit. Note that our setting requires a marginal damage rate that is greater than $\$ 56 / t$ for natural gas units to become more economical than coal units, which would then only be used in peak load periods.

\subsubsection{Computing Market Equilibria}

Given our market model and its calibration to Ontario and Quebec, it is possible to compute hourly market equilibria for the three regimes under study, as seen in Propositions 1-4. The implementation of the model requires finding the unique value of $\lambda$, the Lagrange multiplier associated with "Total water availability," which is such that all markets balance. Given transaction costs, either exports, imports or no trade happen between the two jurisdictions.

A single constraint binds electricity supply in Quebec: the sum of Quebec hydropower production cannot exceed 184.7 TWh over all hours of the year:

$$
\sum_{t=1}^{8760} e_{t}^{H} \leq 184,705,000
$$

Basic properties of the different cases were used to compute actual equilibrium: price is equal to marginal cost in Ontario and to average cost in Quebec in the first two regimes (here, average cost is $\$ 27.90 / \mathrm{MWh}$ for regime 2, while it is $\$ 29.02 / \mathrm{MWh}$ in regime 1 , due to the absence of imports from Ontario to Quebec); exports and imports are done at Ontario's marginal cost. Under integration, Ontario and Quebec prices are equal, unless transmission capacity becomes binding.

Transmission capacity constraints provided upper and lower bounds on trade, and constrained prices were computed. The challenge consisted in finding the single Quebec price that would make use of all the available hydropower, while respecting all the (first-order) conditions of the problem. As shown in propositions 1 and 3, the problem can be solved by optimization. In regime 3, there is a single price for every hour in Quebec, because the Quebec price is the shadow cost of water, which is unique throughout the year.

\section{RESULTS FOR THE THREE REGIMES}

\subsection{Calibrated Model Results}

Our model of the 2007 Ontario $(T h)$ and Quebec $(H)$ markets is calibrated to reflect actual trade between these two jurisdictions under a mixed market structure (shallow integration). In 2007, Ontario exported 1.93 TWh to Quebec, and imported 0.807 TWh from Quebec, for a net export total of $1.123 \mathrm{TWh}$. Our model of shallow integration (regime 2 or R2) mirrors the export and import numbers exactly. Prices for Ontario were not a perfect match, as we used the real price for 2007 instead (see Table 3). Our R2 model slightly overestimated Ontarian prices (\$48.52/MWh, on average, against a real average hourly price of \$47.81), the Ontario export price to Quebec (\$38.84/ MWh against \$37.15) and the import price to Ontario (\$71/MWh against \$67.20). The Quebec average price was obviously the same, because it was taken directly from the 2007 data. 
Table 3: Price Results

\begin{tabular}{lccrr}
\hline Average price \$/MWh & 2007 Data* & R1 & R2 & R3 \\
\hline$p^{T h}$ & 47.81 & 47.96 & 48.52 & 46.79 \\
$p^{H}$ & 27.90 & 29.02 & 27.90 & 30.91 \\
Export from $T h$ & 37.15 & - & 38.84 & 22.80 \\
Export from $H$ & 67.20 & - & 71.00 & 53.88 \\
Min $p^{T h}$ & $-0.4 * *$ & 4.60 & 4.60 & 4.60 \\
Max $p^{T h}$ & 436.53 & 167.66 & 165.39 & 165.39 \\
\hline
\end{tabular}

*Average Ontario export and Quebec export prices are computed from HQ TransÉnergie (2009) and IESO (2008a).

**This negative price occurred during an August night and is among a few outliers. Figure 2 shows that minimum prices are at about $\$ 4$.

Table 4: Supply and Demand Results

\begin{tabular}{lcccc}
\hline TWh & 2007 Data & R1 & R2 & R3 \\
\hline$\sum D_{t}^{T h}$ & 162.25 & 162.39 & 161.94 & 162.85 \\
$\sum D_{t}^{H}$ & 185.82 & 184.70 & 185.82 & 182.823 \\
Total Demand & 348.083 & 347.09 & 347.77 & 345.67 \\
$\sum e_{t}^{T h}$ & n.a. & 162.39 & 163.06 & 160.96 \\
$\sum e_{t}^{H}$ & n.a. & 184.70 & 184.70 & 184.70 \\
Share of Trade* & n.a. & $0 \%$ & $0.79 \%$ & $0.83 \%$ \\
\hline
\end{tabular}

*Sum of exports and imports over overall demand.

The differences between the three regimes-autarky (R1), shallow integration (R2) and deep integration (R3) — are notable. Autarky brings slightly lower average prices to Ontario, as the province does not have to produce more to export to Quebec. In Quebec, because there is less available energy, prices are also higher $(\$ 29.02 / \mathrm{MWh}$ against \$27.90). Fully integrating both markets by using marginal cost pricing (with limited transmission capacity) increases the Quebec price by $\$ 3 / \mathrm{MWh}(+10.8 \%)$, while the Ontario price goes down to $\$ 46.79 / \mathrm{MWh}(-3.5 \%)$, as it gains access to more imports from Quebec.

The marginal value of water in $\mathrm{R} 2(\lambda=\$ 58.73)$ is about twice that in $\mathrm{R} 3(\lambda=\$ 30.91)$. Because water is used less efficiently in R2 than in R3 it makes more of a difference to have water available, hence the higher value. When transmission capacity doubles (see section 4.2), the value of water in $\mathrm{R} 2$ decreases to $\lambda=\$ 53.48$, as some additional efficiency is gained through increased trade.

Table 4 provides the demand and supply quantities resulting from the prevailing prices. Ontario's demand (using a demand price elasticity of -0.15$)$ slightly increases in autarky $(+0.27 \%$, due to lower prices) compared to shallow integration. With deep integration, demand increases by $0.56 \%$, again due to lower prices. In Quebec, the opposite happens: $-0.6 \%$ in autarky and $-1.62 \%$ under deep integration, compared to shallow integration. On the supply side, relatively important generation reductions occur in Ontario: almost $1 \mathrm{TWh}$ would not be generated in autarky $(-0.42 \%)$, while $3 \mathrm{TWh}(-1.29 \%)$ less would be produced under deep integration. Of course, these reductions lead to lower profits for Ontarian generators, as shown in Table 5. Obviously, supply from Quebec remains stable at $184.70 \mathrm{TWh}$. Total trade increases with shallow integration (from R1 to R2) and again with deep integration (R3). This share still remains a small fraction of total consumption. 
Table 5: Welfare Impacts

\begin{tabular}{lccrr}
\hline Million \$ & 2007 Data & R1 & R2 & R3 \\
\hline Change of Consumer Surplus $T h$ & n.a. & +61 & - & +275 \\
Change of Consumer Surplus $H$ & n.a. & -208 & - & -554 \\
Change of Profit $T h$ & n.a. & -63 & - & -275 \\
Change of Profit $H$ & n.a. & +198 & - & +601 \\
\hline Consumer Surplus + Profit & n.a. & -12 & - & +47 \\
\hline Coal Emissions (million t) & & 28.74 & 29.29 & 28.60 \\
NG Emissions (million t) & & 8.86 & 8.90 & 8.31 \\
Total Emissions (million t) & 34 & 37.60 & 38.19 & 36.92 \\
\hline
\end{tabular}

Table 6: Total Welfare Impacts

\begin{tabular}{lccc}
\hline Change in Million \$ & $\mathrm{R} 1$ & $\mathrm{R} 2$ & $\mathrm{R} 3$ \\
\hline Th CS + Profit & -2.41 & - & +0.30 \\
$H$ CS + Profit & -10.28 & - & +47.12 \\
Total CS + Profit & -12.70 & - & +47.42 \\
Marginal Damage Th $(@ 20 \$ / \mathrm{t})$ & -11.80 & - & -25.52 \\
Marginal Damage $H(@ 20 \$ / \mathrm{t})$ & -11.80 & - & -25.52 \\
Total Damage $(@ 40 \$ / \mathrm{t})$ & -23.61 & - & -51.05 \\
\hline Total Welfare $(\mathrm{CS}+$ Profit-Damage $)$ & +10.91 & - & +98.47 \\
\hline
\end{tabular}

While Ontarian consumers marginally increase their surplus in autarky $(+\$ 61$ million, or $\$ 4.76$ per capita), they benefit more from integration ( + \$275 million, or $\$ 21.50$ per capita) (see Table 5). Quebec consumers, on the other hand, lose much more in either case: $-\$ 27.05$ per capita ( $-\$ 208$ million globally) with autarky, or $-\$ 71.97$ per capita ( $-\$ 554$ million) with integration, as they lose access to regulated low-price electricity. However, the limited transmission capacity "protects" them against a further increase. Sharing a similar outcome, Ontarian producers see their profits decrease with lower production levels, both in autarky ( $-\$ 63$ million) and integration ( $-\$ 275$ million). It is clear from these results that while consumers in Quebec do not want integration, opposition would also be strong from Ontario's producers. Profit for the Quebec producer, however, would increase considerably thanks to higher local prices and additional exports, made at an even higher price (as compared to the local price). In the integrated regime (R3), as compared to shallow integration (R2), additional profits in Quebec ( $+\$ 601$ million) are more than twice the decrease in profits faced by Ontarian producers ( $-\$ 275$ million). Net gains per capita would amount to $-\$ 0.62$ from regime 2 to 1 , and to $\$ 2.31$ from regime 2 to 3 , without accounting for GHG emissions. As emissions would decrease by $1.76 \mathrm{Mt}$ from regime 2 to 3 , while welfare would increase by $\$ 47$ million (see Table 5), we obtain an abatement cost of minus $\$ 37.16 /$ t. This result, although expected, is striking as GHG emission reduction efforts are usually associated with a positive cost.

When damage from emissions is accounted for, as illustrated in Table 6, regime 2 is clearly the worst in terms of total welfare. Indeed, total emissions (especially from coal power plants) increase from R1 to R2 ( + 1.5\%). The damage is therefore lower in an autarky, as shown in Table 5. This comes from Quebec's imports from Ontario in off-peak periods, which are in part re-exported during peak periods. Under integration, total emissions decrease by $3.34 \%$, as power plants in 
Table 7: Price Results for Twice the Transmission Capacity

\begin{tabular}{lrrrr}
\hline Average price \$/MWh & $\mathrm{R} 2$ & $\mathrm{R} 3$ & $\mathrm{R} 2 \times 2$ & $\mathrm{R} 3 \times 2$ \\
\hline$p^{T h}$ & 48.52 & 46.79 & 48.41 & 45.80 \\
$p^{H}$ & 27.90 & 30.91 & 27.90 & 32.48 \\
Export from $T h$ & 38.84 & 22.80 & 37.60 & 24.97 \\
Export from $H$ & 71.00 & 53.88 & 65.24 & 52.91 \\
Min $p^{T h}$ & 4.60 & 4.60 & 4.60 & 4.60 \\
Max $p^{T h}$ & 165.39 & 165.39 & 163.12 & 163.12 \\
\hline
\end{tabular}

Ontario are used less often. Let us again emphasize, as illustrated in Table 6, that these reductions in GHG emissions come with an overall improvement of welfare.

Only if the cost of damage was lower than $\$ 21.5 / \mathrm{t}$ would trade gains made under shallow integration (R2) be greater than the environmental cost resulting from higher emissions. Interpreted differently, removing transmissions (going from R2 to R1) would lead to lower emissions and lower welfare, corresponding to an abatement cost of $\$ 21.5 / \mathrm{t}$.

\subsection{Doubling Transmission Capacity}

In the previous section, all results were presented for transmission capacities between 93 and $451 \mathrm{MW}$ for flows from Quebec to Ontario, and 92 to $391 \mathrm{MW}$ for flows from Ontario to Quebec. These transmission capacities were adjusted from reported maximum transmission capacities to better model actual 2007 exchanges between the two provinces. It is interesting to analyze the impact of an increase in transmission capacity between the two jurisdictions, as was the case in 2010, with the addition of about 1,000 MW of transmission capacity. This was an initiative of the Quebec producer. In this section, we provide results for twice the initial modeled transmission capacity.

A doubling of the transmission capacity under shallow integration (R2 x2) and deep integration (R3 x2) further decreases the price in Ontario, compared to the initial outcome (reproduced in Table 7). In Quebec, a price increase only occurs under deep integration (as average cost is no longer used), and is significantly higher than earlier (\$32.48/MWh compared to \$30.91 with half the transmission capacity). Increased transmission capacity also reduces export and import prices, with the exception of Ontario's export price, which rises from $\$ 22.80 / \mathrm{MWh}$ to $\$ 24.97$ under integration. There are actually two price effects. The increase in arbitrage across periods that follows from augmented trade capacities tends to reduce the price gap between import and export periods in Ontario. ${ }^{13}$ In addition, there is an average price effect that follows from changes in net traded volume. In particular, under deep integration, Quebec becomes a net exporter of electricity (from a net importer under shallow integration), because more hydropower is available for exports as a result of lower consumption in the province.

Observed trends in relation to consumption and production (in Table 4) are again shown in Table 8. One exception, however, is worth mentioning: total consumption in Ontario goes down with increased transmission $(-0.08 \%)$, despite a lower (unweighted) average price ${ }^{14}(-0.22 \%$;

13. The Quebec producer imports as much as possible during low-price periods and re-exports at a higher price. These additional Quebec imports from Ontario increase the Ontario (export) price, while re-exporting this energy decreases the (Ontario) import price.

14. A weighted average price would weigh hourly price by hourly consumption. 
Table 8: Supply and Demand Results for Twice the Transmission Capacity

\begin{tabular}{lcccc}
\hline TWh & R2 & R3 & R2 x2 & R3 x2 \\
\hline$\sum D_{t}^{T h}$ & 161.94 & 162.85 & 161.81 & 163.20 \\
$\sum D_{t}^{H}$ & 185.82 & 182.823 & 185.82 & 181.25 \\
Total Demand & 347.77 & 345.67 & 347.64 & 344.46 \\
$\sum e_{t}^{T h}$ & 163.06 & 160.96 & 162.93 & 159.75 \\
$\sum e_{t}^{H}$ & 184.70 & 184.70 & 184.70 & 184.70 \\
Share of Trade* & $0.79 \%$ & $0.83 \%$ & $1.53 \%$ & $1.62 \%$ \\
\hline
\end{tabular}

*Sum of exports and imports over overall demand.

Table 9: Impacts of Doubling Transmission Capacity on Welfare

\begin{tabular}{lcccc}
\hline Million \$ & R2 & R3 & R2 x2 & R3 x2 \\
\hline Change of Consumer Surplus Th & - & +275 & +54 & +466 \\
Change of Consumer Surplus $H$ & - & -554 & 0 & -840 \\
Change of Profit $T h$ & - & -275 & -84 & -458 \\
Change of Profit $H$ & - & 601 & 32 & 931 \\
\hline Consumer Surplus + Profit & - & +47 & +2 & +99 \\
\hline Coal Emissions (million t) & 29.29 & 28.60 & 29.67 & 28.53 \\
NG Emissions (million t) & 8.90 & 8.31 & 8.62 & 7.82 \\
Total Emissions (million t) & 38.19 & 36.92 & 38.34 & 36.36 \\
\hline
\end{tabular}

Table 7). This is due to the fact that hourly patterns lead to both an increase in some prices as well as some decreases. On an hourly basis, changes are consistent with the price-quantity relationship, but on the aggregate, a smaller average price and a lower total consumption are observed. Quebec consumption decreases by $0.86 \%$ in the $\mathrm{R} 3 \times 2$ case, as compared to R3. This is $2.46 \%$ less than consumption under shallow integration ( $\mathrm{R} 2 \times 2$ or $\mathrm{R} 2$; since the price is regulated in regime 2, Quebec's consumption is identical in both cases). Overall, total demand decreases by $0.95 \%$ in R3 $\mathrm{x} 2$ as compared to $\mathrm{R} 2$.

Table 9 shows losses and gains similar to those found in Table 5. Additional transmission capacity further increases consumer surplus in Ontario, while it further reduces the consumer surplus in Quebec (except under R2 x2, where the price remains constant for consumers despite greater access to the Ontarian market). Ontarian producers' profits continue to shrink, while the Quebec producer's profits continue to rise. This is an important driver for the addition of transmission capacity. Export revenues grow in all cases, as would be expected with greater trade opportunities. Emissions worsen under shallow integration with increased transmission capacity $(+0.39 \%)$, especially due to more intense imports in off-peak periods. Coal emissions increase, while natural gas emissions decrease. In the R3 x2 case, emissions decrease even more $(-1.52 \%)$, as compared to $\mathrm{R} 3$. The abatement cost for the additional emissions is $-\$ 91.86 / \mathrm{t}$, as a result of high profits made as some hydropower replaces natural gas. This value comes from the welfare and emission differences between R3 x 2 and R3, as shown in Table 9 .

Table 10 shows that more trade (through greater integration and/or increased transmission capacity) increases welfare, before accounting for environmental damage. As shown by Billette de Villemeur and Pineau (2012), this was not necessarily expected, as price regulation may result in 
Table 10: Impacts of Doubling Transmission Capacity on Total Welfare

\begin{tabular}{lcccc}
\hline Change in Million \$ & $\mathrm{R} 2$ & $\mathrm{R} 3$ & $\mathrm{R} 2 \times 2$ & $\mathrm{R} 3 \times 2$ \\
\hline Th CS + Profit (Billion) & - & +0.30 & -29.39 & +8.02 \\
$H$ CS + Profit (Billion) & - & +47.12 & +32.00 & +90.94 \\
Total CS + Profit (Billion) & - & +47.42 & +2.61 & +98.96 \\
Marginal Damage Th (@ 20\$/t, Billion) & - & -25.52 & +3.00 & -36.75 \\
Marginal Damage $H$ (@ 20\$/t, Billion) & - & -25.52 & +3.00 & -36.75 \\
Total Damage (40\$/t, Billion) & - & -51.05 & +6.00 & -73.5 \\
Total Welfare $(\mathrm{CS}+$ Profit-Damage) & - & +98.47 & -3.38 & +172.45 \\
\hline
\end{tabular}

inefficient trade. As a matter of fact, in regime 2, the welfare gains that follow from doubling the capacity are very low. Beyond this, we illustrate with this example that increasing trade under shallow integration can be welfare-damaging, even if the Quebec producer's profits would increase. After accounting for damage from emissions, the net gain from trade might indeed be negative. Only if the total damage per tonne were lower than $\$ 17.40$ would the trade gain be greater than any additional damage. Another interpretation for this value of $\$ 17.40 / \mathrm{t}$ is that it represents the abatement cost of emissions through a reduction of transmission capacity between the two markets (under shallow integration).

Note also that additional transmission investment costs are not accounted for in these regimes. A more thorough analysis should include them.

Our results can however help in determining the social profitability of the expansion of transmission capacity. For instance, over a lifetime of 40 years and using a discount rate of $6 \%$, doubling transmission capacity would be worth $\$ 1.11$ billion under regime 3. By contrast, even if carried out at no cost, increasing transmission would never be socially profitable in regime 2 .

\section{CONCLUSION}

This paper offers both a theoretical and an empirical perspective on the welfare impacts of integrating electricity markets, in a context of a given generating capacity. Such integration is on the political agendas of many governments and institutions, but it is seldom analyzed theoretically or empirically. We proposed a multi-period two-jurisdiction electricity market model to study integration impacts in terms of welfare implications and emissions, with insights on their distribution. This model looked at a competitive thermal jurisdiction with a marginal pricing policy and a hydro one with an average-cost pricing regulation. A detailed calibration was made using production and demand data from Ontario and Quebec (two Canadian provinces).

Under different integration regimes (autarky, shallow integration and deep integration), we obtained results showing how production, price and emissions evolve. This modeling effort is the paper's first contribution, as, to date, the literature has not focused on comparable detailed integration outcomes. The second contribution comes from estimates of GHG abatement costs in the electricity sector, resulting from integration. Since electricity is an important contributor to world GHG emissions, abatement opportunities with negative costs (as is the case in this paper) should be contemplated.

Numerical results show that increasingly lower prices would be observed in the thermal jurisdiction if deep integration was implemented $(-3.5 \%)$ and transmission capacity doubled (a further $-2.1 \%$ ). This benefits consumers, but not producers in the thermal jurisdiction. On the contrary, in the hydro jurisdiction, consumers would face higher prices (and therefore lose some 
surplus) with deep integration $(+10.8 \%)$ and increased transmission capacity $(+5.1 \%)$, while profit would significantly increase for the hydro producer. Emissions follow the thermal producers' fate: they decrease as integration develops. Remarkably in a world where the reduction of GHG emissions is often associated with a cost, a negative abatement cost is obtained: $-\$ 37.16 / t$ under deep integration, jumping to $-\$ 91.86 /$ f for the additional reduction that would follow a doubling of transmission capacity.

This paper also serves as an important warning. Under shallow integration, i.e., when the hydro jurisdiction sticks to its average pricing policy, any additional trading can lead to higher emission levels - if base load units are more carbon intensive than peak load ones. In other words, if institutional settings continue to be overlooked when integrating electricity markets, combining a hydro jurisdiction to a thermal one is actually likely to be environmentally damaging.

\section{ACKNOWLEDGMENTS}

We thank the three anonymous referees for their constructive comments. Pierre-Olivier Pineau also acknowledges the support of the HEC Montréal Chair in Energy Sector Management. This paper was initiated while the first author was Visiting Professor at Université de Montreal and completed during subsequent regular visits for which the hospitality of the economic department is gratefully acknowledged.

\section{REFERENCES}

BC Hydro (2012). "BC Hydro Annual Report 2012.” Vancouver: BC Hydro.

Billette de Villemeur, E. and P.-O. Pineau (2010). "Environmentally Damaging Electricity Trade.” Energy Policy 38 (3): 1548-1558. http://dx.doi.org/10.1016/j.enpol.2009.11.038.

Billette de Villemeur, E. and P.-O. Pineau (2012). "Regulation and Electricity Market Integration: When Trade Introduces Inefficiencies." Energy Economics 34 (2): 529-535. http://dx.doi.org/10.1016/j.eneco.2011.12.004.

Billette de Villemeur, E. and A. Vinella (2011). "Long-term contracting in hydro-thermal electricity generation: Welfare and environmental impact.” Utilities Policy 19 (1): 20-32. http://dx.doi.org/10.1016/j.jup.2010.06.003.

ECA (2010). "The Potential of Regional Power Sector Integration - Literature Review.” London: Economic Consulting Associates

EIA (2007). "Assumptions to the Annual Energy Outlook 2007.” Washington D.C.: Energy Information Administration, Department of Energy.

Environment Canada (2008). "National Inventory Report 1990-2006 - The Canadian Government's Submission to the UN Framework Convention on Climate Change." Ottawa: Environment Canada.

Environment Canada (2009). "National Inventory Report 1990-2007 - The Canadian Government's Submission to the UN Framework Convention on Climate Change." Ottawa: Environment Canada.

EPRI (2007). “Assessment of Waterpower Potential and Development Needs.” Palo Alto: Electric Power Research Institute. FERC (2005). "Remedying Undue Discrimination through Open Access Transmission Service and Standard Electricity Market Design - Order Terminating Proceeding.” Washington D.C.: Federal Energy Regulatory Commission, Docket No. RM01-12-000.

Finon, D. and E. Romano (2009). "Electricity market integration: Redistribution effect versus resource allocation." Energy Policy 37 (8): 2977-2985. http://dx.doi.org/10.1016/j.enpol.2009.03.045.

Førsund, F.R. (2007). Hydropower Economics:112. International Series in Operations Research \& Management Science. Boston: Springer. http://dx.doi.org/10.1007/978-0-387-73027-1.

Førsund, F.R., Singh, B., T. Jensen and C. Larsen (2008). "Phasing in wind-power in Norway: network congestion and crowding-out of hydropower.” Energy Policy 36 (9): 3514- 3520. http://dx.doi.org/10.1016/j.enpol.2008.06.005.

Green, R. and N. Vasilakos (2012). "Storing Wind for a Rainy Day: What Kind of Electricity Does Denmark Export?" The Energy Journal 33(3): 1-22. http://dx.doi.org/10.5547/01956574.33.3.1.

Hall D.G. and K.S. Reeves (2006). "A Study of United States Hydroelectric Plant Ownership.” Idaho Falls: Idaho National Laboratory, INL/EXT-06-11519. http://dx.doi.org/10.2172/911556.

Copyright (C) 2016 by the IAEE. All rights reserved. 
HQ TransÉnergie (2006). “Our System at a Glance.” Montréal: Hydro-Québec, web page accessed February 2, 2009. http:// www.hydroquebec.com/transenergie/en/reseau/bref.html

HQ TransÉnergie (2009). "Yearly Logs - Schedules 2007.” OASIS Transmission services Montréal: Hydro-Québec.

Hydro-Québec (2008). “Annual Report 2007.” Montréal: Hydro-Québec.

Hydro-Québec Production (2009). "Thermal and Nuclear Generating Stations.” Montréal: Hydro-Québec, web page accessed February 2, 2009. http://www.hydroquebec.com/generation/classics/index.html

IEA (2005). "Projected Costs of Generating Electricity - 2005 Update." Paris: International Energy Agency.

IESO (2007). "Monthly Generator Disclosure Report.” Toronto: Independent Electricity System Operator.

IESO (2008a). "Hourly Ontario Energy Price, Market Data.” IESO Public Reports Toronto: Independent Electricity System Operator.

IESO (2008b). "Hourly Demands, Market Data.” IESO Public Reports. Toronto: Independent Electricity System Operator. IESO (2009). "2009 Ontario Market Outlook.” Toronto: Independent Electricity System Operator.

IESO (2013). "Ontario Reserve Margin Requirements, 2014-2018.” Toronto: Independent Electricity System Operator.

IFC (2002). "Economic Assessment of RTO Policy." Fairfax: ICF Consulting.

IPCC (2007). "Climate Change 2007: Synthesis Report - An Assessment of the Intergovernmental Panel on Climate

Change." World Meteorological Organization (WMO) and the United Nations Environment Programme (UNEP).

Lijesen, M. G. (2007). "The real-time price elasticity of electricity.” Energy Economics 29(2): 249-258. http://dx.doi.org/ 10.1016/j.eneco.2006.08.008.

MRNF (2009). "Puissance des centrales électriques." Québec: Ministère des Ressources Naturelles et Faune, web page accessed February 2, 2009. http://www.mrn.gouv.qc.ca/energie/statistiques/statistiques-production-centrales.jsp

NERC (2008). "Electricity Supply \& Demand 2007." Princeton: North American Electric Reliability Corporation.

NERC (2011). "Glossary of Terms Used in NERC Reliability Standards - Updated October 26 2011.” Princeton: North American Electric Reliability Corporation.

Newbery, D.M. (2000). Privatization, Restructuring, and Regulation of Network utilities. Second Printing Cambridge: The MIT Press.

Pineau, P.-O. (2013). “Fragmented Markets: Canadian Electricity Sectors' Underperformance.” In F.P. Sioshansi, ed., Evolution of Global Electricity Markets: New paradigms, new challenges, new approaches. Waltham, MA: Academic Press. Chapter 13. http://dx.doi.org/10.1016/B978-0-12-397891-2.00013-4.

Pineau, P.-O. and V. Lefebvre (2009). "The Value of Unused Interregional Transmission: Estimating the Opportunity Cost for Quebec (Canada).” International Journal of Energy Sector Management 3(4): 406-423. http://dx.doi.org/10.1108/ 17506220911005768.

Province of British Columbia (2009). "Backgrounder - B.C.'s Revenue-neutral Carbon Tax.” webpage accessed on January 15th 2009, 3:20 p.m. http://www.bcbudget.gov.bc.ca/2008/backgrounders/backgrounder_carbon_tax.htm

Rangel, L. F. (2008). "Competition policy and regulation in hydro-dominated electricity markets." Energy Policy 36(4): 1292-1302. http://dx.doi.org/10.1016/j.enpol.2007.12.005.

Statistics Canada (2009). "Electric Power Generation, Transmission and Distribution 2007.” Ottawa: Statistics, Canada Catalogue no. 57-202-X.

Stoft, S. (2002). Power Systems Economics: Designing Markets for Electricity. Piscataway: IEEE Press and New York: Wiley-Interscience. http://dx.doi.org/10.1109/9780470545584.

Tol, R.S.J. (2005). "The marginal damage costs of carbon dioxide emissions: an assessment of the uncertainties." Energy Policy 33(16): 2064-2074. http://dx.doi.org/10.1016/j.enpol.2004.04.002.

UN (2006). "Multi Dimensional Issues in International Electric Power Grid Interconnections." Department of Economic and Social Affairs, Division for Sustainable Development, New York: United Nations.

UNECA (2006). “Assessing Regional Integration in Africa II: Rationalizing Regional Economic Communities.” Addis Ababa: United Nations Economic Commission for Africa and African Union.

WEC (2005). "Regional Energy Integration in Africa." London: World Energy Council.

World Bank (2010). "Regional Power Sector Integration: Lessons from Global Case Studies and a Literature Review, Regional Energy Integration Strategies Program - Solving Energy Challenges through Regional Cooperation.” Energy Sector Management Assistance Program, Washington, DC: The World Bank.

Zareipour, H., Bhattacharya, K. and C.A. Cañizares (2007). "Electricity market price volatility: The case of Ontario." Energy Policy 35(9): 4739-4748. http://dx.doi.org/10.1016/j.enpol.2007.04.006. 


\section{A. PROOF}

\section{Proof of Proposition 2}

Proposition 2: In regime 2, when $T h$ is exporting, the price in $T h$ is at most $\overline{p_{T h}}=\lambda-c^{\tau}$. When $T h$ is importing, the price in $T h$ is no less than $p_{T h}=\lambda+c^{\tau}$. If $x_{t}^{T h}=x_{t}^{H}=0$ then:

$$
\overline{p_{T h}}<p_{t}^{T h}=C_{T h}^{\prime}\left(e_{t}^{T h}\right)<\underline{p_{T h}} .
$$

The proof of Proposition $\mathbf{2}$ is based upon the following intermediate result:

Proposition 2.1 Computing the equilibrium in regime 2 amounts to solving the optimization program:

$$
\begin{aligned}
& \max _{\left\{e_{t}^{T h}, x_{t}^{T h}, x_{t}^{H}\right\}_{t=1, \ldots, 8760}}\left\{\sum_{t=1}^{8760}\left[\int_{0}^{e_{t}^{T h}+x_{t}^{H}-x_{t}^{T h}} p_{t}^{T h}(q) d q-C_{T h}\left(e_{t}^{T h}\right)-c^{\tau} x_{t}^{T h}-c^{\tau} x_{t}^{H}\right]\right\} \\
& \text { s.t. } \sum_{t=1}^{87600}\left(x_{t}^{H}-x_{t}^{T h}\right) \leq W-\sum_{t=1}^{8760} D_{t}^{H}\left(p_{R}^{H}\right) \text { and }-\bar{x}_{t}^{T h} \leq x_{t}^{H}-x_{t}^{T h} \leq \bar{x}_{t}^{H},
\end{aligned}
$$

all $t=1, \ldots, 8760$.

Let $L$ denote the Lagrangian associated with the optimization problem of Proposition 1:

$$
\begin{aligned}
& L=\sum_{t=1}^{8760}\left[\int_{0}^{e_{t}^{T h}+x_{t}^{H}-x_{t}^{T h}} p_{t}^{T h}(q) d q-C_{T h}\left(e_{t}^{T h}\right)-c^{\tau} x_{t}^{T h}-c^{\tau} x_{t}^{H}\right] \\
& +\lambda\left\{W-\sum_{t=1}^{8760}\left[D_{t}^{H}\left(p_{R}^{H}\right)+x_{t}^{H}-x_{t}^{T h}\right]\right\}+\sum_{t=1}^{8760}\left[\mu_{t}^{H}\left(\bar{x}_{t}^{H}-x_{t}^{H}+x_{t}^{T h}\right)+\mu_{t}^{T h}\left(\bar{x}_{t}^{T h}-x_{t}^{T h}+x_{t}^{H}\right)\right] .
\end{aligned}
$$

Absent transmission constraints, price patterns are easily characterized. The FOC $\left(\partial L / \partial e_{t}^{T h}\right)=0$ implies that $p_{t}^{T h}=C_{T h}^{\prime}\left(e_{t}^{T h}\right)$.

If $x_{t}^{H}>0$, then $\left(\partial L / \partial x_{t}^{H}\right)=0$ yields $p_{t}^{T h}=\lambda+c^{\tau}$; if $x_{t}^{T h}>0$, then $\left(\partial L / \partial x_{t}^{T h}\right)=0$ yields $p_{t}^{T h}=\lambda-c^{\tau}$; if $x_{t}^{T h}=x_{t}^{H}=0$ then we have:

$$
\lambda-c^{\tau} \leq p_{t}^{T h}=C_{T h}^{\prime}\left(e_{t}^{T h}\right) \leq \lambda+c^{\tau} .
$$

From the optimization program of Proposition $\mathbf{1}$ and by definition of the hourly Lagrange multipliers of the transmission constraint $\mu_{t}^{H}$ and $\mu_{t}^{T h}$, when $H$ is exporting, that is $x_{t}^{H}>0$, but the transmission constraint is binding, we have $\mathrm{e}^{15}$

$$
p_{t}^{T h}=\lambda+c^{\tau}+\mu_{t}
$$

with $\mu_{t}=\mu_{t}^{H} \geq 0$ (and $\mu_{t}^{T h}=0$ ). Thus $p_{t}^{T h} \geq \underline{p_{T h}}$.

15. This is the first-order condition obtained by derivation of the Lagrangian with respect to the $x_{t}^{H}$. 
Similarly, when $T h$ is exporting, that is $x_{t}^{T h}>0$, but the transmission constraint is binding, then ${ }^{16}$

$$
p_{t}^{T h}=\lambda-c^{\tau}-\mu_{t}
$$

with $\mu_{t}=\mu_{t}^{T h} \geq 0$ (and $\mu_{t}^{H}=0$ ). Thus $p_{t}^{T h} \leq \overline{p_{T h}}$.

If $\overline{p_{T h}}<p_{t}^{T h}<p_{T h}$, the marginal benefits from trade are strictly lower than the transmission costs $c^{\tau}$. It is both welfare- and profit-maximizing to restrain from trading. Clearly, we still have $p_{t}^{T h}=C_{T h}^{\prime}\left(e_{t}^{T h}\right)$.

\section{Proof of Proposition 4}

Proposition 4: In regime 3, when $T h$ is exporting, the price in $T h$ is at most $\overline{p_{T h}}=p_{e}^{H}-c^{\tau}$ When $T h$ is importing, the price in $T h$ is no less than $\underline{p_{T h}}=p_{e}^{H}+c^{\tau}$. If $x_{t}^{T h}=x_{t}^{H}=0$ then:

$$
\overline{p_{T h}}<p_{t}^{T h}=C_{T h}^{\prime}\left(e_{t}^{T h}\right)<\underline{p_{T h}} .
$$

The equality $p_{t}^{H}=p_{e}^{H}=\lambda$ is obtained from the first-order condition associated with the choice of $e_{t}^{H}$ in the optimization program of Proposition 3. The demonstration is then identical to that of Proposition 2 above.

\section{B. ESTIMATING QUEBEC HOURLY DEMAND}

For an hour $t$ (in a month $m$ ), the Quebec demand $D_{t}^{H}$ is estimated by an affine transformation of Ontario's demand $\left(D_{t}^{T h}\right)$ :

$$
D_{t}^{H}=\gamma_{m} D_{t}^{T h}+\delta_{m}
$$

In order to compute $\gamma_{m}$ and $\delta_{m}$, for every month observed, we use the ratio between Quebec and Ontario peak demands $\left(r_{m}^{\text {peak }}\right)$ and total consumption $\left(r_{m}^{\text {total }}\right)$, as illustrated in Figure 1:

$$
r_{m}^{\text {peak }}=\frac{D_{\text {peak }}^{H}}{D_{\text {peak }}^{T h}} \text { and } r_{m}^{\text {total }}=\frac{\sum D_{t}^{H}}{\sum D_{t}^{T h}} .
$$

This results in

$$
\begin{aligned}
\gamma_{m} & =\frac{\sum D_{t}^{H}-N_{m} D_{\text {peak }}^{H}}{\sum D_{t}^{T h}-N_{m} D_{\text {peak }}^{T h}} \\
\delta_{m} & =\left(r_{m}^{\text {peak }}-\gamma_{m}\right) D_{\text {peak }}^{T h}
\end{aligned}
$$

where $N_{m}$ is the number of hours in month $m$.

To summarize, we took hourly Ontario prices from IESO (2008a) and hourly Ontarian demand from IESO (2008b). With NERC (2008) and the above affine transformation, we estimated hourly Quebec demands. The price of energy in Quebec was set at \$27.90/MWh.

16. This is the first-order condition obtained by derivation of the Lagrangian with respect to the $x_{t}^{T h}$. 